\title{
Viewpoint \\ The role of single nucleotide polymorphisms in breast cancer metastasis
}

\author{
James M Rae ${ }^{1}$, Todd C Skaar², Susan G Hilsenbeck ${ }^{3}$ and Steffi Oesterreich ${ }^{3}$ \\ ${ }^{1}$ Division of Hematology Oncology, Department of Internal Medicine, University of Michigan Medical Center, Ann Arbor, MI 48109, USA \\ 2Division of Clinical Pharmacology, Indiana University School of Medicine, Indianapolis, IN 46202, USA \\ ${ }^{3}$ The Breast Center, Department of Medicine, and Molecular and Cellular Biology, Baylor College of Medicine, Houston, TX 77030, USA
}

Corresponding author: James M Rae, jimmyrae@umich.edu

Published: 18 January 2008

This article is online at http://breast-cancer-research.com/content/10/1/301

(c) 2008 BioMed Central Ltd
Breast Cancer Research 2008, 10:301 (doi:10.1186/bcr1842)

tion of the causal genetic variants in these models may lead to the identification of important metastasis genes and heritable genetic variants that predispose humans to breast cancer metastasis. Using the MMTV-PyMT transgenic mouse model, which develops mammary tumors with 100\% penetrance, Hunter and colleagues [5] have shown that the incidence of pulmonary metastasis was influenced by the mouse genetic background. They found that the AKR and FVB stains show high metastatic efficiency, while two others (DBA and NZB) show low rates of metastasis. Quantitative trait genetic mapping analysis identified a probable metastasis efficiency locus (Mtes1) on mouse chromosome 19 in a $10 \mathrm{Mb}$ region orthologous to human chromosome 11q12-13. Although the known metastasis suppressor gene Brms 1 maps to this locus, extensive sequencing efforts failed to identify any genetic polymorphisms. Therefore, a multiple cross-mapping strategy was used to narrow down the number of candidate genes to 23 with known molecular function for further characterization. One of these genes, Sipa1 (signal-induced proliferation-associated gene 1), was found to have a non-synonymous single nucleotide polymorphism (SNP) in a functional domain. It was, therefore, considered to be the top candidate for the metastasis modifier locus Mtes 1.

Sipa1 is a mitogen-inducible GTPase-activating protein that has previously been shown to regulate cell adhesion [6]. Park and colleagues [5] found that the Sipa1 genes of the highly metastatic mouse strains AKR and FVB contain a A739T SNP. This SNP changes a predicted amino acid from an alanine to threonine in the PDZ protein-protein interaction domain. In the COS7 and U373MG non-breast cancer cell lines, functional studies showed that the $T h r$ allele was associated with reduced concentrations of active, GTPbound Rap1. This was due to a weaker interaction between the $739^{\text {Thr }}$ Sipa1 protein with its inhibitor, AQP2, and,

$\mathrm{SNP}=$ single nucleotide polymorphism. 
consequently, less inhibition of Sipa1 activity. Furthermore, they showed that altered Sipa1 expression levels resulted in altered pulmonary metastases.

Although this evidence is consistent with Sipa1 being a metastasis susceptibility gene, one could argue that these data are not sufficient to conclude for certain that the Sipa1 polymorphism is a "constitutional genetic polymorphism affecting tumor metastasis" [5]. To our knowledge, there is no evidence that the A739T polymorphism affects Sipa1 protein levels in living cells; however, functional studies in cells looking at the effect of the SNP were done using cells with different Sipa1 protein levels, and not with cells harboring wild-type or variant Sipa1. The generation of appropriate cell line models for the testing of phenotypes from wild-type and variant genes is clearly a critical challenge in the SNP field, not limited to the here discussed Sipa1 study.

An analysis of the online Oncomine tumor gene expression database [http://www.oncomine.org] showed that Sipa1 was more highly expressed in metastatic compared to primary prostate cancers, although there was no difference in expression between primary breast cancer and metastases. In any case, since the Oncomine database contains only expression levels and not genetic variant statuses, the data in the prostate tumors support the hypothesis that Sipa1 expression levels are associated with metastatic potential, but can not contribute to our knowledge about the role of Sipa1 genetic variants.

To expand on these exciting findings, Crawford and colleagues [7] conducted a case control study to specifically determine whether there is an association between Sipa 1 genetic variants and human breast cancer metastasis. Three SNPs in the Sipa1 gene from the NCBI dbSNP database (G313A, C545T, and G2760A; http://www.ncbi.nlm.nih.gov/ SNP) were genotyped in a case/control study, in which the 'controls' were localized disease (small, well differentiated tumors; $n=146$ ), and the 'cases' were patients with regional or metastatic disease in which the disease had extended to skin, muscle, chest wall, lymph nodes, or beyond $(n=154)$. There was no significant difference in SNP frequency between cases and controls, although significant associations between the G313A and G2760A SNPs and positive lymph nodes were observed, and the C545T allele correlated with estrogen receptor/progesterone receptor negative disease. These studies provide encouraging support for a role of Sipa1 genetic polymorphisms in breast cancer metastasis; however, two important questions remain from this study. First, since studies of multiple SNPs and multiple phenotypes create the potential for multiple comparison problems and frequent false positive results, it would be important to either correct for multiple comparisons or know the predicted false discovery rate. Second, it would be of interest to determine, through additional sequencing studies, whether additional SNPs can be identified in the human
Sipa1 PDZ domain, given that this is the functional domain to which the mouse Sipa1 genetic variant maps. In any case, as with any genetic association study, replication of these findings will be key to confirming their role in breast cancer metastasis.

In conclusion, the hypothesis that germ line polymorphism can influence human breast cancer metastasis is a provocative and very exciting new area of research. The identification of heritable genetic determinants of metastatic potential could have profound effects on cancer treatments by improving cancer treatment decisions. For example, more diligent screening and more aggressive therapies could be used in patients that are constitutionally more likely to develop distal relapses. However, this area of research is still in its infancy. There are many genes known to influence cancer metastasis and whether inherent genetic variations can truly affect metastatic potential in patients is not yet known. The data on the role of Sipa1 are exciting and address a very important and timely topic. However, as acknowledged by the authors, "there is no reason to believe that genes of unknown functions or known genes in pathways not previously associated with metastasis are not also potential candidates" [5], and indeed, a second candidate gene for the Mtes 1 locus is already being investigated in the authors' laboratory. The scientific community should look forward to future studies on the role of candidate genes such as Sipa1 and 'gene $\mathrm{x}$ ' at the Mtes1 locus, as well as to genome-wide association studies in our search for polymorphism(s) as breast cancer metastasis modifiers.

\section{Competing interests}

The authors declare that they have no competing interests.

\section{References}

1. King MC, Marks JH, Mandell JB: Breast and ovarian cancer risks due to inherited mutations in BRCA1 and BRCA2. Science 2003, 302:643-646.

2. Easton DF, Pooley KA, Dunning AM, Pharoah PD, Thompson D, Ballinger DG, Struewing JP, Morrison J, Field H, Luben R, et al:: Genome-wide association study identifies novel breast cancer susceptibility loci. Nature 2007, 447:1087-1093.

3. Hunter DJ, Kraft P, Jacobs KB, Cox DG, Yeager M, Hankinson SE, Wacholder S, Wang Z, Welch R, Hutchinson A, et al:: A genome-wide association study identifies alleles in FGFR2 associated with risk of sporadic postmenopausal breast cancer. Nat Genet 2007, 39:870-874.

4. Choi JY, Nowell SA, Blanco JG, Ambrosone CB: The role of genetic variability in drug metabolism pathways in breast cancer prognosis. Pharmacogenomics 2006, 7:613-624.

5. Park YG, Zhao X, Lesueur F, Lowy DR, Lancaster M, Pharoah P, Qian X, Hunter KW: Sipa1 is a candidate for underlying the metastasis efficiency modifier locus Mtes1. Nat Genet 2005, 37:1055-1062.

6. Tsukamoto N, Hattori M, Yang H, Bos JL, Minato N: Rap1 GTPase-activating protein SPA-1 negatively regulates cell adhesion. J Biol Chem 1999, 274:18463-18469.

7. Crawford NP, Ziogas A, Peel DJ, Hess J, Anton-Culver H, Hunter KW: Germline polymorphisms in SIPA1 are associated with metastasis and other indicators of poor prognosis in breast cancer. Breast Cancer Res 2006, 8:R16. 